\title{
Cumulative Effect of Obesogenic Behaviours on Adiposity in Spanish Children and Adolescents
}

\begin{abstract}
Helmut Schröder ${ }^{\text {a, b }}$ Rowaedh Ahmed Bawaked ${ }^{a, c}$ Lourdes Ribas-Barbad, e Maria Izquierdo-Pulido ${ }^{e} f \quad$ Blanca Roman-Viñas ${ }^{d, e} \quad$ Montserrat Fíto $^{a}$ e Lluis Serra-Majem ${ }^{d, e}, g$

${ }^{a}$ Cardiovascular Risk and Nutrition Research Group (CARIN), IMIM (Hospital del Mar Medical Research Institute), Barcelona, Spain; ${ }^{b}$ CIBER Epidemiology and Public Health (CIBERESP),

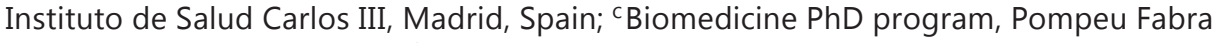
University, Barcelona, Spain; d Fundación para la Investigación Nutricional (Nutrition Research

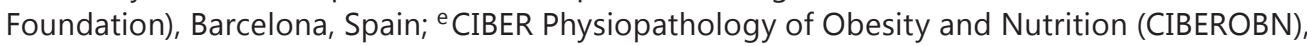
Instituto de Salud Carlos III, Madrid, Spain; ${ }^{f}$ Department of Nutrition, Food Sciences and Gastronomy, University of Barcelona, Barcelona, Spain; ${ }^{9}$ Research Institute of Biomedical and Health Sciences, University of Las Palmas de Gran Canaria, Las Palmas, Spain
\end{abstract}

\section{Keywords}

Childhood obesity · Physical activity · Diet · Obesogenic behaviours

\begin{abstract}
Objective: Little is known about the cumulative effect of obesogenic behaviours on childhood obesity risk. We determined the cumulative effect on BMI z-score, waist-to-height ratio (WHtR), overweight and abdominal obesity of four lifestyle behaviours that have been linked to obesity. Methods: In this cross-sectional analysis, data were obtained from the EnKid sudy, a representative sample of Spanish youth. The study included 1,614 boys and girls aged 5-18 years. Weight, height and waist circumference were measured. Physical activity (PA), screen time, breakfast consumption and meal frequency were self-reported on structured questionnaires. Obesogenic behaviours were defined as $<1 \mathrm{~h} \mathrm{PA} /$ day, $\geq 2 \mathrm{~h} /$ day screen time, skipping breakfast and $<3$ meals/day. BMI $z$-score was computed using age- and sex-specific reference values from the World Health Organization (WHO). Overweight including obesity was defined as a BMI > 1 SD from the mean of the WHO reference population. Abdominal obesity was defined as a WHtR $\geq 0.5$. Results: High screen time was the most prominent obesogenic be-
\end{abstract}

Helmut Schröder and Rowaedh Ahmed Bawaked contributed equally to the study, and each can be considered first authors of this article. 
haviour (49.7\%), followed by low physical activity (22.4\%), low meal frequency (14.4\%), and skipping breakfast (12.5\%). Although 33\% of participants were free of all 4 obesogenic behaviours, 1, 2, and 3 or 4 behaviours were reported by $44.5 \%, 19.3 \%$, and $5.0 \%$, respectively. BMI $z$-score and WHtR were positively associated $(p<0.001)$ with increasing numbers of concurrent obesogenic behaviours. The odds of presenting with obesogenic behaviours were significantly higher in children who were overweight (OR 2.68; 95\% CI 1.50; 4.80) or had abdominal obesity (OR 2.12; 95\% CI 1.28; 3.52); they reported more than 2 obesogenic behaviours. High maternal and parental education was inversely associated $(p=0.004$ and $p<0.001$, respectively) with increasing presence of obesogenic behaviours. Surrogate markers of adiposity increased with numbers of concurrent presence of obesogenic behaviours. The opposite was true for high maternal and paternal education.

(C) 2017 The Author(s)

Published by S. Karger GmbH, Freiburg

\section{Introduction}

The childhood obesity epidemic is among the world's most challenging public health problems, with an especially high prevalence of overweight and obesity in South European countries. At present, 38.6\% of Spanish children and adolescents are overweight or obese [1], and $16.5 \%$ have abdominal obesity [2]. The high obesity prevalence is of concern because premature onset of related illnesses such as diabetes, hypercholesterolaemia and non-alcoholic fatty liver disease is increased among obese children $[3,4]$. Therefore, there is an urgent need to develop effective intervention programmes to curb this troubling epidemic.

Behaviours such as low physical activity, high screen time, skipping breakfast and low meal frequency are prevalent in young populations [5-9], and all of them have been linked to an increased risk of childhood obesity and therefore defined as obesogenic behaviours $[5,6,10-12]$. Most studies investigated the individual impact of these behaviours on obesity risk [5, 6, 10-12]. However, clustering of multiple obesity risk behaviours is well known in young populations [13]. Furthermore, findings indicate that co-occurrence of obesogenic behaviours is associated with lower parental socio-economic status $[14,15]$. Less is known, however, about the cumulative effect of these behaviours on childhood obesity risk [16].

It is important to determine whether adding a second unhealthy lifestyle behaviour significantly increases the effect size of the association with weight gain or obesity. The cumulative effect of the concurrent presence of low physical activity, skipping breakfast, high screen time and low meal frequency would imply a need for multilevel intervention programmes addressing these modifiable behaviours. In this context it is crucial to know if the risk of co-occurrence of multiple obesity risk behaviours differs with parental socioeconomic level. We hypothesized an increase in obesity risk estimates with the co-occurrence of one or more obesogenic behaviours and a relationship between parental socio-economic status and the presences of more than one of these behaviours.

The aim of this study was to determine the individual and cumulative effect of low physical activity, skipping breakfast, high screen time and low meal frequency on BMI, waistto-height ratio (WHtR), overweight and abdominal obesity in a nationwide representative sample of Spanish children and adolescents. A secondary objective was to analyse the association between the concurrent presence of these obesity-related behaviours and parental educational level. 
Schröder et al.: Cumulative Effect of Obesogenic Behaviours on Adiposity in Spanish Children and Adolescents

\section{Material and Methods}

\section{Study Design and Subjects}

The EnKid study on nutritional status and food habits of Spanish children and young people, which was conducted between 1998 and 2000, was a cross-sectional survey of the Spanish population aged 2-24 years, selected by multistage random sampling procedures based on a population census. The objective of the EnKid study was two-fold: i) to establish the prevalence of micronutrient deficiencies in the population aged 2-24 years and ii) to analyse the association of these micronutrients with group membership (gender and age groups). The sample size was calculated according to i) the estimated prevalence of most micronutrients with $95 \%$ confidence interval and accuracy of $5 \%$ of the average value of the micronutrient and ii) a statistical power of $80 \%$ to detect significant differences between two groups $>10 \%$ of the mean of the micronutrients (setting the alpha error at $p=0.05$ ). The calculated sample size of 3,850 individuals was over-estimated by $30 \%$, resulting in a theoretical sample size of 5,500 individuals. The final sample size of the EnKid study was 3,534 individuals. The final study sample consisted of 1,614 individuals aged 5-18 years. Data were collected by trained dietitians during a personal interview with each participant or, for those younger than 8 years, with the mother or the person responsible for feeding the child. All field workers received training prior to data collection. Parental written consent was obtained on behalf of each participant under 18 years. The study protocol was approved by the ethics committee of the Spanish Society of Community Nutrition.

\section{Anthropometric Measurements}

For each participant, the following anthropometric measurements were assessed according to standard protocols: Body weight height, and waist circumference were measured on the day of the interview, with the subject in underwear without shoes, using an electronic scale (to the nearest $100 \mathrm{~g}$ ), a portable Kawe stadiometer (to the nearest $1 \mathrm{~mm}$ ) and a Hoechst metric tape (to the nearest $1 \mathrm{~mm}$ ). Using a flexible non-stretch tape measure, waist circumference was measured by trained interviewers in the narrowest zone between the lower costal rib and iliac crest, in the supine decubitus and horizontal positions. Excessive abdominal fat was defined as WHtR $>0.50$.

BMI $z$-score was computed using age- and sex-specific reference values from the World Health Organization (WHO) [17]. Overweight and obesity were defined as BMI $>1$ SD $<2$ SD and BMI $>2$ SD, respectively, from the mean of the WHO reference population.

\section{Physical Activity, Screen Time and Dietary Habits}

Physical activity was recorded by a structured questionnaire including one question about frequency and duration of active games during free time after the school or during the weekend, one question about frequency and duration of physical education class at school, three questions about frequency and duration of walking, and six questions about sport activities outside the school. The questions about sports activities were derived from a validated questionnaire [18]. Physical activity-induced energy expenditure was calculated using the following algorithm: Physical activity-induced energy expenditure = physical activity (in $\mathrm{min} /$ day) $\times$ metabolic equivalent of task $($ MET) $\times$ resting metabolic rate [19] $\times$ body weight (in $\mathrm{kg}$ ). We assigned the MET value of 4.2 to all participants because detailed data on the intensity of each physical activity were not available. Data on regular breakfast consumption and overall meal frequency were recorded. Questions on screen time included watching television, DVDs/videos, using a computer for fun and playing computer or video games.

\section{Obesogenic Behaviour Score}

To determine the cumulative effect of obesogenic behaviours, we calculated a composite obesogenic behaviour score. One point was allocated to low physical activity, defined as $<1 \mathrm{~h} /$ day, high screen time $(>2$ $\mathrm{h} /$ day of television and computer use), no daily breakfast consumption and low meal frequency $(<3$ eating occasions/day). The final score ranged from 0 to 4 points, with higher scores indicating cumulative unhealthy obesogenic behaviours. We combined participants with 3 and 4 obesogenic behaviours as one group because only $0.7 \%$ presented with all 4 obesity-related behavioural risk factors.

\section{Energy Intake and Misreporting}

Energy and macronutrient consumption was assessed from two 24-hour recalls. The 2nd 24-hour recall was completed in a random sample of $25 \%$ of the participants at an independent non-consecutive day. To 
avoid bias brought on by day-to-day intake variability, the questionnaires were administered homogeneously from Monday to Sunday. We included this sentence in the method section of the manuscript. The administration of the 2nd questionnaire allowed for the adjustment of intakes for random intra-individual variation using the method described by Liu et al. [20].

Information was collected at the home of the participant, using household measures to estimate portion sizes. Basal metabolic rate (BMR) was estimated using Schofield's equations based on sex, age, weight and height [19]. Implausible reporters of energy intake were identified by replacing Goldberg's single cut-off [21] with age- and sex-specific cut-offs. The cut-off values were the 95\% confidence limits of the agreement between physical activity level (PAL) and the ratio of energy intake to BMR. The following formula was used:

$$
\text { Cutoff = PAL } x \exp \left\lceil \pm 1.96 \times \frac{\left(\frac{S}{100}\right)}{\sqrt{n}}\right\rceil
$$

where

$$
s=\sqrt{\left[\frac{C V_{w E I}^{2}}{d}+C V_{w B M R}^{2}+C V_{t P}^{2}\right]}
$$

Intra-individual variations of energy intake $\left(\mathrm{CV}^{2}{ }_{\text {wEI }}\right)$ and $\mathrm{BMR}\left(\mathrm{CV}^{2}{ }_{\text {wBMR }}\right)$ and inter-individual variation in physical activity level $\left(\mathrm{CV}^{2}{ }_{\mathrm{wtP}}\right)$ were calculated using sex- and age-specific reference values [22-24]. The single Goldberg PAL of 1.55 was replaced by sex- and age-dependent PAL for adolescents.

\section{Socio-Economic Status}

Determination of socio-economic status was based on maternal and paternal educational level. A high level of education was defined as studying beyond secondary education.

\section{Statistical Analysis}

General linear models were used to define mean values of socio-demographic and lifestyle variables according to numbers of obesogenic behaviours. To define the p value for linear trends, we used polynomial contrast for continuous normal distributed variables, chi-square test for categorical variables and KruskalWallis $\mathrm{H}$ test for non-parametric variables.

Additionally, we fitted confounder-adjusted general linear models to determine the association of the cumulative effect of obesogenic behaviours with BMI z-score and WHtR. A Bonferroni correction was used to correct for multiple comparisons.

Logistic regression was performed to assess the effect of the cumulative obesogenic behaviours on obesity, abdominal obesity, and maternal and paternal education educational level adjusted for potential confounders. Taking the minimum value as the reference ( 0 obesogenic risk factors), odds ratios (ORs) were estimated using the spline technique, which gives smoothed estimates when large differences were unlikely to be observed between OR estimates corresponding to two consecutive exposure values.

Cubic spline analysis was performed using the 'gam' package in R version 3.0.2. Statistical analysis was performed using SPSS version 18.0 (SPSS Inc. Chicago, IL, USA).

\section{Results}

Overall, 31\% of the children did not report any of the four obesogenic behaviours and $44.5 \%$ reported engaging in just one, while $19.3 \%$ and $5.0 \%$ reported three and all four behaviours, respectively. The reported behaviours and combinations $(<4)$ were distributed as follows: 1 behaviour - high screen time (28.4\%), low physical activity (8.4\%), low meal frequency (4.3\%), and skipping breakfast (3.4\%); 2 behaviours - low physical activity + high screen time (9.1\%), high screen time + low meal frequency (4.1\%), skipping breakfast + low meal frequency (1.1\%), low physical activity + skipping breakfast $(0.7 \%)$, and low physical activity + low meal frequency (0.7\%); 3 behaviours - low physical activity+ high screen time+ skipping breakfast $(0.8 \%)$, low physical activity+ high screen time+ low meal frequency $(1.4 \%)$, low physical activity + skipping breakfast + low meal frequency (0.6\%) and high screen time +skipping breakfast + low meal frequency (1.6\%). High screen time was the most 
Schröder et al.: Cumulative Effect of Obesogenic Behaviours on Adiposity in Spanish Children and Adolescents

Table 1. Demographic and lifestyle characteristics of participants according to the cumulative effect of obesogenic behaviours ${ }^{1}$

\begin{tabular}{|c|c|c|c|c|c|}
\hline & \multicolumn{5}{|c|}{ Obesogenic behaviours } \\
\hline & $\begin{array}{l}0 \\
(n=502)\end{array}$ & $\begin{array}{l}1 \\
(n=719)\end{array}$ & $\begin{array}{l}2 \\
(n=312)\end{array}$ & $\begin{array}{l}3-4 \\
(n=81)\end{array}$ & p value ${ }^{2}$ \\
\hline Age, years & $11.4(3.68)$ & $12.5(3.60)$ & $13.4(3.63)$ & $14.8(2.80)$ & $<0.001$ \\
\hline Girls, n (\%) & $249(49.6)$ & $346(48.1)$ & $161(51.6)$ & $55(67.9)$ & 0.032 \\
\hline BMI z-score & $0.49(1.12)$ & $0.49(1.10)$ & $0.65(1.18)$ & $0.71(0.99)$ & 0.016 \\
\hline WHtR & $0.45(0.05)$ & $0.45(0.05)$ & $0.46(0.06)$ & $0.46(0.06)$ & 0.047 \\
\hline Overweight, n (\%) & $143(28.5)$ & $223(31.0)$ & $117(37.5)$ & $27(66.7)$ & 0.019 \\
\hline Abdominal obesity, n (\%) & $76(15.1)$ & $122(17.0)$ & $64(20.5)$ & $14(17.3)$ & 0.102 \\
\hline Maternal education ${ }^{3}, \mathrm{n}(\%)$ & $135(26.9)$ & 139 (19.3) & $46(14.7)$ & $13(16.0)$ & $<0.001$ \\
\hline Paternal education ${ }^{3}, \mathrm{n}(\%)$ & $163(32.5)$ & $186(25.9)$ & $65(20.8)$ & $13(16.0)$ & $<0.001$ \\
\hline Physical activity, min/day & $144(96 ; 204)$ & $132(7)$ & $54(24 ; 144)$ & $40(16 ; 77)$ & $<0.001$ \\
\hline PAEE, kcal/day & $542(355 ; 814)$ & $520(280 ; 885)$ & $227(107 ; 668)$ & $166(82 ; 375)$ & $<0.001$ \\
\hline Low physical activity ${ }^{4}, \mathrm{n}(\%)$ & $0(0.00)$ & $136(18.9)$ & $170(54.5)$ & $55(67.9)$ & $<0.001$ \\
\hline High screen time ${ }^{5}, \mathrm{n}(\%)$ & $0(0.00)$ & $458(63.7)$ & $272(87.2)$ & $72(88.9)$ & $<0.001$ \\
\hline Skipping breakfast ${ }^{6}, \mathrm{n}(\%)$ & $0(0.00)$ & $55(7.65)$ & $87(27.9)$ & $59(72.8)$ & $<0.001$ \\
\hline Low meal frequency ${ }^{7}, \mathrm{n}(\%)$ & $0(0.00)$ & $70(9.74)$ & $95(30.4)$ & $68(84.0)$ & $<0.001$ \\
\hline Energy, kcal/day & $2,158(730)$ & $2,153(800)$ & $2,075(725)$ & $1,744(632)$ & $<0.001$ \\
\hline Carbohydrate, $\% \mathrm{E}^{8}$ & 46.0 & 45.9 & 46.0 & 46.0 & 0.779 \\
\hline Protein, $\% \mathrm{E}^{8}$ & 14.9 & 15.9 & 15.4 & 16.3 & 0.165 \\
\hline Fat, $\% \mathrm{E}^{8}$ & 39.1 & 38.2 & 39.6 & 38.7 & 0.317 \\
\hline EI/EEPA & $3.7(2.5 ; 5.7)$ & $3.8(2.2 ; 6.9)$ & $7.3(2.8 ; 15.3)$ & $8.7(3.5 ; 18.9)$ & $<0.001$ \\
\hline Energy underreporting, n (\%) & $58(11.6)$ & $118(16.4)$ & $49(15.7)$ & $23(28.4)$ & 0.001 \\
\hline Community size, $\mathrm{n}(\%)$ & & & & & 0.920 \\
\hline$<10,000$ inhabitants & $113(22.5)$ & $168(23.4)$ & 77 (24.7) & $25(30.9)$ & \\
\hline $10,000-49,999$ inhabitants & $146(29.1)$ & 207 (28.8) & $66(21.2)$ & $15(18.5)$ & \\
\hline $50,000-350,000$ inhabitants & $126(25.1)$ & $176(24.5)$ & $100(32.1)$ & $19(23.5)$ & \\
\hline$>350,000$ inhabitants & $117(23.3)$ & $168(23.4)$ & $69(22.1)$ & $22(27.2)$ & \\
\hline Region of Spain, n (\%) & & & & & $<0.001$ \\
\hline Centre & $103(20.5)$ & $156(21.7)$ & $66(21.2)$ & $17(21.0)$ & \\
\hline Northeast & $151(30.1)$ & $169(23.5)$ & $53(17.0)$ & $16(19.8)$ & \\
\hline North & $132(26.3)$ & $166(23.1)$ & $81(26.0)$ & $23(28.4)$ & \\
\hline South & $60(12.0)$ & $121(16.8)$ & $52(16.7)$ & $13(16.0)$ & \\
\hline East & $47(9.4)$ & $89(12.4)$ & $47(15.1)$ & $5(6.2)$ & \\
\hline Canary Islands & $9(1.8)$ & $18(2.5)$ & $13(4.2)$ & $7(8.6)$ & \\
\hline
\end{tabular}

EI:PAEE = Energy intake: physical activity energy expenditure; PAEE = physical activity energy expenditure; WHtR = waistto-height ratio.

${ }^{1}$ General linear models were used to determine the association of sociodemographic and lifestyle variables according to numbers of obesogenic behaviours. Values are expressed as mean (standard deviation), median (interquartile range) and number $(\%)$.

${ }^{2}$ p values were obtained by ANOVA, Kruskal-Wallis, and Pearson's chi square for normal continuous, non-normal continuous, and categorical variables, respectively.

${ }^{3}$ University degree.

${ }^{4}$ Physical activity $<60 \mathrm{~min} /$ day.

${ }^{5}$ Screen time $>2 \mathrm{~h} /$ day.

${ }^{6}$ No daily breakfast.

${ }^{7}$ Fewer than 4 meals per day.

${ }^{8}$ Percentage of energy consumption. 
Schröder et al.: Cumulative Effect of Obesogenic Behaviours on Adiposity in Spanish Children and Adolescents

Table 2. Adjusted general linear models of the association of obesogenic behaviours (OB) and BMI z-score and waist-to-height ratio (WHtR) of 1614 boys and girls of the EnKid study ${ }^{1}$

\begin{tabular}{|c|c|c|c|c|c|c|c|}
\hline & \multirow[t]{2}{*}{ n (\%) } & \multicolumn{2}{|l|}{ BMI z-score } & \multirow[t]{2}{*}{$\mathrm{p}$ value } & \multicolumn{2}{|l|}{ WHtR } & \multirow[t]{2}{*}{$\mathrm{p}$ value } \\
\hline & & OB absent & OB present & & OB absent & OB present & \\
\hline \multicolumn{8}{|l|}{ Individual $O B$} \\
\hline Low physical activity ${ }^{2}$ & $\begin{array}{l}361 \\
(22.4)\end{array}$ & $\begin{array}{l}0.47 \\
(0.41 ; 0.53)\end{array}$ & $\begin{array}{l}0.74 \\
(0.63 ; 0.85)\end{array}$ & $<0.001$ & $\begin{array}{l}0.449 \\
(0.447 ; 0.452)\end{array}$ & $\begin{array}{l}0.46 .3 \\
(0.458 ; 0.468)\end{array}$ & $<0.001$ \\
\hline High screen time ${ }^{3}$ & $\begin{array}{l}802 \\
(44.5)\end{array}$ & $\begin{array}{l}0.49 \\
(0.41 ; 0.56)\end{array}$ & $\begin{array}{l}0.58 \\
(0.51 ; 0.65)\end{array}$ & 0.077 & $\begin{array}{l}0.451 \\
(0.447 ; 0.454)\end{array}$ & $\begin{array}{l}0.454 \\
(0.451 ; 0.457)\end{array}$ & 0.223 \\
\hline Skipping breakfast ${ }^{4}$ & $\begin{array}{l}201 \\
(12.5)\end{array}$ & $\begin{array}{l}0.52 \\
(0.46 ; 0.57)\end{array}$ & $\begin{array}{l}0.63 \\
(0.48 ; 0.78)\end{array}$ & 0.100 & $\begin{array}{l}0.451 \\
(0.448 ; 0.453)\end{array}$ & $\begin{array}{l}0.465 \\
(0.458 ; 0.472)\end{array}$ & 0.001 \\
\hline Low meal frequency ${ }^{5}$ & $\begin{array}{l}233 \\
(14.4)\end{array}$ & $\begin{array}{l}0.51 \\
(0.45 ; 0.57)\end{array}$ & $\begin{array}{l}0.67 \\
(0.56 ; 0.80)\end{array}$ & 0.041 & $\begin{array}{l}0.452 \\
(0.450 ; 0.455)\end{array}$ & $\begin{array}{l}0.453 \\
(0.447 ; 0.460)\end{array}$ & 0.796 \\
\hline \multicolumn{8}{|l|}{ Cumulative $O B$} \\
\hline None & $\begin{array}{l}502 \\
(31.1)\end{array}$ & $\begin{array}{l}0.43 \\
(0.34 ; 0.53)\end{array}$ & & & $\begin{array}{l}0.447 \\
(0.442 ; 0.451)\end{array}$ & & \\
\hline $1 \mathrm{OB}$ & $\begin{array}{l}719 \\
(44.5)\end{array}$ & & $\begin{array}{l}0.48 \\
(0.41 ; 0.56)\end{array}$ & & & $\begin{array}{l}0.451 \\
(0.448 ; 0.455)\end{array}$ & \\
\hline $2 \mathrm{OB}$ & $\begin{array}{l}312 \\
(19.3)\end{array}$ & & $\begin{array}{l}0.73 \\
(0.61 ; 0.85)\end{array}$ & & & $\begin{array}{l}0.461 \\
(0.455 ; 0.466)\end{array}$ & \\
\hline $3 / 4$ OB & $\begin{array}{l}81 \\
(5)\end{array}$ & & $\begin{array}{l}0.87 \\
(0.63 ; 1.11)\end{array}$ & & & $\begin{array}{l}0.467 \\
(0.457 ; 0.478)\end{array}$ & \\
\hline P for linear trend ${ }^{6}$ & & & $<0.001$ & & & $<0.001$ & \\
\hline \multicolumn{8}{|c|}{$\begin{array}{l}{ }^{1} \text { Values are expressed as mean (95\% confidence interval) and adjusted for sex, age, region, community size, matern } \\
\text { ducation, energy, and energy over and underreporting. }\end{array}$} \\
\hline
\end{tabular}

prominent obesogenic behaviour (49.7\%) followed by low physical activity (22.4\%), low meal frequency (14.4\%) and skipping breakfast (12.5\%). Low physical activity / high screen time and high screen time / skipping breakfast / low meal frequency were the most prevalent combinations within clusters of 2 behaviours and more than 2 behaviours, respectively. Estimation of the effect of different combinations of obesogenic behaviours on the association with the risk of overweight and abdominal obesity was not possible due to the limited statistical power. The accumulation of obesogenic risk factors was positively associated with age, BMI z-score, the ratio between energy intake and physical activity-induced energy expenditure and WHtR, whereas the opposite was true for physical activity and energy intake (table 1). The proportion of girls and of children with obesity, abdominal obesity and low/ medium level of parental education increased with co-occurrence of obesogenic behaviours. A northeast to south gradient was observed for the accumulation of obesogenic behaviours, with the Canary Island as the region with the highest risk.

Multivariate analysis of the association between the cumulative effects of obesogenic behaviours and BMI z-score or WHtR revealed a difference of 0.50 SD for BMI z-score and of 0.025 for WHtR between participants with no obesogenic risk behaviours and those with 
Schröder et al.: Cumulative Effect of Obesogenic Behaviours on Adiposity in Spanish Children and Adolescents

Table 3. Adjusted* logistic regression analysis of the association of individual and cumulative obesogenic behaviours (OB) with overweight and abdominal obesity of 1614 boys and girls of the EnKid study ${ }^{1}$

\begin{tabular}{|c|c|c|c|c|c|}
\hline & \multirow[t]{2}{*}{ N (\%) } & \multicolumn{2}{|c|}{ Overweight/obesity } & \multicolumn{2}{|c|}{ Abdominal obesity } \\
\hline & & OR & $(95 \% \mathrm{CI})$ & OR & $(95 \% \mathrm{CI})$ \\
\hline \multicolumn{6}{|l|}{ Individual $O B$} \\
\hline Low physical activity ${ }^{2}$ & $361(22.4)$ & 1.87 & $(1.31 ; 2.68)$ & 1.69 & $(1.24 ; 2.32)$ \\
\hline High screen time ${ }^{3}$ & $802(44.5)$ & 1.36 & $(0.99 ; 1.88)$ & 1.13 & $(0.85 ; 1.49)$ \\
\hline Skipping breakfast ${ }^{4}$ & $201(12.5)$ & 1.23 & $(0.77 ; 1.98)$ & 1.52 & $(1.02 ; 2.28)$ \\
\hline Low meal frequency ${ }^{5}$ & $233(14.4)$ & 1.05 & $(0.64 ; 1.72)$ & 0.86 & $(0.55 ; 1.33)$ \\
\hline \multicolumn{6}{|l|}{ Cumulative $O B$} \\
\hline None & $502(31.1)$ & 1 & & 1 & \\
\hline $10 B$ & $719(44.5)$ & 1.39 & $(1.14 ; 1.69)$ & 1.28 & $(1.08 ; 1.52)$ \\
\hline $2 \mathrm{OB}$ & $312(19.3)$ & 1.93 & $(1.31 ; 2.85)$ & 1.65 & $(1.18 ; 2.31)$ \\
\hline $3 / 4 \mathrm{OB}$ & $81(5)$ & 2.68 & $(1.50 ; 4.80)$ & 2.12 & $(1.28 ; 3.52)$ \\
\hline Linear trend & & & $<0.001$ & & 0.004 \\
\hline \multicolumn{6}{|c|}{$\begin{array}{l}{ }^{1} \text { Logistic regression models adjusted for sex, age, region, community size } \\
\text { ad energy over and underreporting. Individual OB were mutually adjusted. } \\
{ }^{2} \text { Physical activity }<1 \mathrm{~h} / \text { day. } \\
{ }^{3} \text { Screen time }>2 \mathrm{~h} / \text { day. } \\
{ }^{4} \text { No daily breakfast. } \\
{ }^{5} \text { Less than } 4 \text { meals per dav. }\end{array}$} \\
\hline
\end{tabular}

three or more (table 2). At the individual level, all obesogenic behaviours, with the exception of high screen time, were significantly related to increased levels of at least one surrogate marker of adiposity (table 2). All models were adjusted for age, sex, region, community size, maternal education, energy intake and energy under- and over-reporting.

Multivariate logistic models adjusted for sex, age, region, community size, energy intake and energy under- and over-reporting showed higher odds of overweight and abdominal obesity for children with increasing numbers of obesogenic behaviours, compared to those having none of the risk behaviours (table 3). In participants with at least 3 obesogenic behaviours, the odds of being overweight and having abdominal obesity increased by $168 \%$ and $112 \%$ respectively, compared to those with none. Low physical activity was associated with significantly higher odds of overweight and abdominal obesity, whereas skipping breakfast increased the odds for abdominal obesity.

The odds of parents having higher education levels decreased as the number of obesogenic behaviours increased (fig. 1). Participants with 3 or more obesogenic behaviours had $52.0 \%$ and $59.0 \%$ higher odds of low maternal and paternal education, respectively, compared to their peers without obesogenic behaviours (fig. 1).

To determine the robustness of our data, we performed sensitivity analysis, fitting multivariate models of the association between two main outcomes (BMI z-score and WHtR) and categories of obesogenic behaviours stratified by sex and age group (children aged 5-12 years vs. adolescents aged 13-17 years) (table 4). The effect sizes of the associations were similar in boys and girls but stronger in adolescents. 
Schröder et al.: Cumulative Effect of Obesogenic Behaviours on Adiposity in Spanish Children and Adolescents

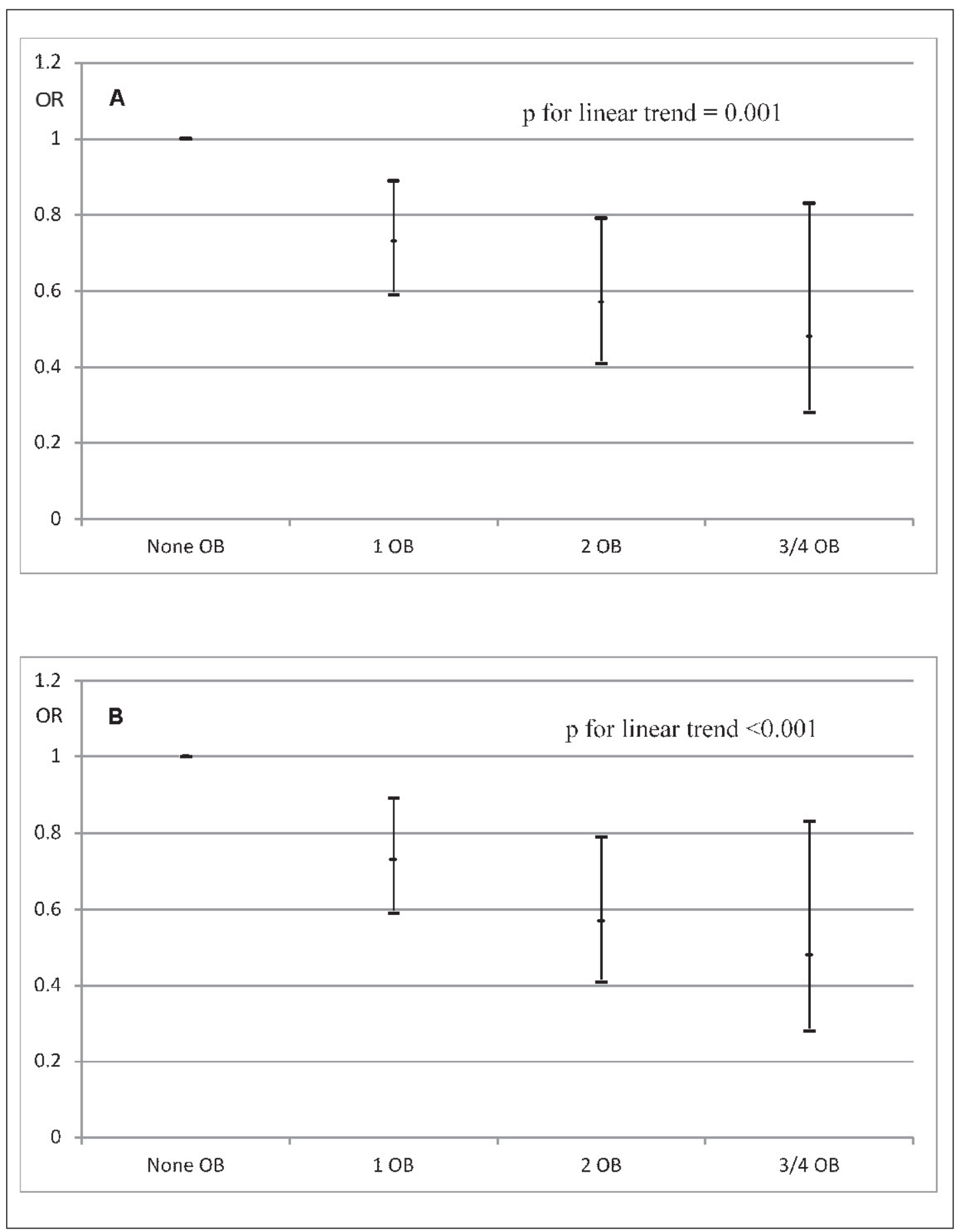

Fig. 1. Odds ratio (OR) of the association between cumulative obesogenic behaviours (OB) and high maternal (A) and paternal (B) education adjusted for sex, age, region, community size, energy and energy under- and over-reporting. 
Schröder et al.: Cumulative Effect of Obesogenic Behaviours on Adiposity in Spanish Children and Adolescents

Table 4. Adjusted general linear models of the association of cumulative obesogenic behaviors and BMI z-score and WHtR stratified by sex and age ${ }^{1}$

\begin{tabular}{lllllll}
\hline & $\mathrm{n}(\%)$ & None & 1 OB & 2 OB & $3 / 4$ OB & p for trend $^{2}$ \\
\hline BMI z-score & & & & & & \\
Boys & 803 & 0.56 & 0.60 & 0.96 & 1.30 & $<0.001$ \\
& $(49.8)$ & $(0.42 ; 0.71)$ & $(0.48 ; 0.72)$ & $(0.77 ; 1.14)$ & $(0.85 ; 1.74)$ & \\
Girls & 811 & 0.30 & 0.38 & 0.50 & 0.56 & 0.049 \\
& $(50.2)$ & $(0.18 ; 0.42)$ & $(0.28 ; 0.48)$ & $(0.35 ; 0.65)$ & $(0.30 ; 0.83)$ & \\
WHtR & & & & & \\
Boys & 803 & 0.458 & 0.461 & 0.476 & 0.486 & 0.003 \\
& $(49.8)$ & $(0.452 ; 0.465)$ & $(0.456 ; 0.466)$ & $(0.467 ; 0.484)$ & $(0.467 ; 0.51)$ & \\
Girls & 811 & 0.435 & 0.442 & 0.447 & 0.453 & 0.007 \\
& $(50.2)$ & $(0.429 ; 0.440)$ & $(0.437 ; 0.446)$ & $(0.440 ; 0.454)$ & $(0.440 ; 0.465)$ & \\
\hline BMI z-score & & & & & & \\
Children & 662 & 0.68 & 0.72 & 1.02 & 1.17 & 0.076 \\
& $(41.0)$ & $(0.52 ; 0.80)$ & $(0.58 ; 0.85)$ & $(0.51 ; 1.82)$ & $(0.51 ; 1.82)$ & \\
Adolescents & 952 & 0.28 & 0.32 & 0.54 & 0.70 & 0.001 \\
& $(59.0)$ & $(0.15 ; 0.41)$ & $(0.22 ; 0.41)$ & $(0.41 ; 0.67)$ & $(0.46 ; 0.94)$ & \\
WHtR & & & & & \\
Children & 662 & 0.461 & 0.468 & 0.475 & 0.468 & 0.500 \\
Adolescents & $(41.0)$ & $(0.456 ; 0.467)$ & $(0.462 ; 0.473)$ & $(0.466 ; 0.485)$ & $(0.442 ; 0.495)$ & \\
& $(59.0)$ & 0.437 & 0.440 & 0.450 & 0.459 & $<0.001$ \\
& $(0.431 ; 0.444)$ & $(0.435 ; 0.444)$ & $(0.443 ; 0.457)$ & $(0.447 ; 0.471)$ & \\
\hline
\end{tabular}

WHtR = Waist-to-height ratio.

${ }^{1}$ Values are expressed as mean (95\% confidence interval). Adjusted for sex, age, region, community size, maternal education, energy, and energy over and underreporting.

${ }^{2}$ Polynomial contrast. Bonferroni correction was used to correct for multiple comparisons.

\section{Discussion}

The risk of overweight and abdominal obesity in Spanish children and adolescents increased with the number of concurrent obesogenic behaviours analysed - including low physical activity, high screen time, skipping breakfast, and low meal frequency. Additionally, BMI z-score and WHtR increased with number of these obesogenic behaviours. Higher parental educational level was less prevalent in the group reporting multiple obesogenic behaviours. In the present study, we observed the highest risk for obesogenic behaviours in the Canary Islands, which corresponds to a report of 2000 [25] that Gran Canary (the largest island) had the highest prevalence of childhood obesity in Spain. Further research is needed to establish the cause for the high prevalence of obesogenic behaviours, especially considering that cardiovascular mortality in the Canary Islands was among the highest in Spain at the same time [26], an unfortunate distinction with an increasing trend according to a 2009 white paper for the 2015-2017 Health Plan for the Canary Islands [27]. The report emphasised that the community had the highest mortality rates related to ischaemic heart disease and diabetes in Spain and presented the highest rates of obesity, both overall and in children and youth, making actions to combat sedentary lifestyles and overweight a public health priority. A strong positive association has been established between obesity and fatal coronary heart disease [28].

Individual lifestyle behaviours identified as a potential cause of the obesity epidemic in children and adolescents, i.e. obesogenic behaviours, are highly prevalent in European coun- 
tries [5-9]. The East of England Healthy Hearts study revealed that 36\% of English children aged 10-15 years spent more than $2 \mathrm{~h}$ daily in screen time [7]. Not meeting the recommended screen time limit was reported in half of all Spanish children aged 5-14 years [8]. Two-thirds and four-fifths of European boys and girls, respectively, were engaged in less than 60 min/day of moderate to vigorous physical activity [29]. Skipping breakfast and low meal frequency were somewhat less prevalent $[5,6]$.

In the present study, the high proportion of children and adolescents with obesogenic behaviours was in line with these previous reports. We also found that not meeting the recommended physical activity level, skipping breakfast and high screen time were associated with at least one surrogate marker of adiposity, as already shown in previous studies $[5,6,11,12]$. In contrast to a recently published meta-analysis [10], however, we did not found any significant relationship between low meal frequency and BMI z-score, WHtR, obesity or abdominal obesity. It must be noted that individual reports included in this meta-analysis showed controversial results; when stratified by sex, the significance of the association persisted only in boys. In the most recent contribution to the debate about the impact of meal timing and frequency on cardiovascular disease risk factors, the American Heart Association concluded that the current evidence of impact is more consistent for obesity than it is for diabetes [30].

Overlapping obesity risk behaviours is frequent in young populations [31]. It has been suggested that obesogenic behaviours interact and exert a cumulative effect on weight gain [15], although the underlying mechanisms are poorly understood. A recent review by Leech and collaborators [31] summarised the current evidence on the association of diet, physical activity and sedentary behaviour with overweight and obesity. The authors considered only articles which determined clustering patterns of these behaviours by data-driven methodologies. Based on these data, they postulated that evidence is inconclusive to postulate an association between clustering of these behaviours and excess weight. Another approach is to define a priori clusters based on the number of risk behaviours. This methodology has shown that unhealthy lifestyle behaviours cumulatively increase the risk of cardiovascular disease, cancer and premature death in adult populations [32-34]. Sanchez and collaborators [15] observed a cumulative effect of low physical activity, high television viewing, high fat intake and low fruit and vegetable consumption on the risk of overweight in adolescents. The AVENA (Alimentación y Valoración del Estado Nutricional de los Adolescentes) study [16] analysed the combined impact of physically inactivity, low sleep duration, high television viewing and low meal frequency on total and abdominal body fat and the risk of overweight in Spanish adolescents. Total fat and abdominal fat significantly increased with the number of obesogenic behaviours, and the odds of overweight increased with the number of groups of risk behaviours reported [16].

The findings present here are in line with these previous reports. BMI z-score and WHtR - surrogate markers of general and abdominal adiposity - increased with the number of obesogenic behaviours. These findings indicate a synergistic impact of these behaviours, showing a more detrimental impact of combinations of risk behaviours on adiposity in comparison to the sole presence of only one of these risk behaviours. Furthermore, the observed difference of 0.42 standard deviations in BMI z-score between children with no obesity risk behaviours and those with more than 2 is important. Decreasing the BMI z-score by at least 0.25 standard deviations improved insulin sensitivity, the total to high-density cholesterol ratio and blood pressure in children [35,36]. Abdominal obesity also increased as numbers of obesogenic behaviours increased. This is of particular concern given the detrimental effect of abdominal obesity on health in young populations [37].

Parental socio-economic status is a crucial determinant for childhood obesity [38]. Previous studies indicated that the percentage of high parental education decreases with the number of obesity risk behaviours [15]. In the present study, children of families with high maternal and/or paternal educational level were less vulnerable to co-occurrence of obeso- 
genic behaviours. The increasing number of obesogenic behaviours was also positively associated with age. Driskel and collaborators [39] reported that $9.1 \%$ and $20.8 \%$ of elementary schoolers present 0 and 3 risk behaviours, respectively. In contrast, only $4.7 \%$ of high schoolers present no risk behaviour and $30.6 \%$ reported 3 risk behaviours. Age is a critical factor in the adoption of obesogenic risk behaviours.

A limitation of this study is the cross-sectional study design, which precludes drawing causal relationships.

It should be noted that the EnKid study data are now 17 years old, which could raise questions about their current relevance in young people. Obesogenic behaviours remain highly prevalent in Spanish children and adolescents, who are increasingly sedentary. For example, average screen time has increased from the $1.6 \mathrm{~h} /$ day reported in the EnKid data (2000) to $2.5 \mathrm{~h} /$ day in 2013 [40], and Spain's 2016 report card on physical activity for children and youth showed that recommended physical activity levels are not being met [41]. In this context, our findings based on the EnKid data remain timely, although the effect size of the associations might have changed. Two further limitations were that exposure was selfreported (and therefore prone to recall bias) and cardiovascular risk factors were not measured (so the relationship between cardiometabolic health and obesogenic behaviours could not be addressed). Physical activity was calculated by a questionnaire including validated and non-validated questions. This might increase the risk of measurement error.

The study also has important strengths, including a nationwide population-based sample and measured anthropometric variables.

\section{Conclusion}

The cumulative effect of low physical activity, high screen time, skipping breakfast and low meal frequency increased the risk of higher BMI z-scores, higher WHtR and higher odds of overweight and abdominal obesity in a representative population of Spanish children and adolescents. Parental educational level was strongly related to the concurrent presence of these obesogenic behaviours. Multilevel behaviour modifications in early life can be a promising strategy to reduce the subsequent obesity risk.

\section{Acknowledgements}

We appreciate the English revision by Elaine M. Lilly, Ph.D. This work was supported by grants from the Spanish Ministry of Health (RED: Alimentación saludable en la prevención primaria de enfermedades crónicas: la Red Predimed, one of the Redes Temáticas de Investigación Cooperativa Sanitaria (RETICs)) Fundación Dieta Mediterránea, Spain; and Kellogg's España SA and Kellogg's Company, Battle Creek, USA via the Fundación Universitaria de Las Palmas de Gran Canaria and the Fundación para la Investigación Nutricional and by King Abdullah scholarship programme (2014,ID 2631), Instituto de Salud Carlos III FEDER (CB06/02/0029), AGAUR (2014 SGR 240). The CIBERESP and the CIBEROBN and the RETIC Predimed are initiatives of the Instituto de Salud Carlos III, Madrid, Spain. The funders had no role in study design, data collection and analysis, decision to publish or preparation of the manuscript.

\section{Authors' Contributions}

HS and RAB conducted the analysis and prepared the manuscript, with significant input and feedback from all co-authors. HS, RAB, LRB, MIP, BRF, MF and LSM participated in the design and execution of the study and contributed to the critical revision of the manuscript for important intellectual content. All authors approved the final version of the manuscript. 
Schröder et al.: Cumulative Effect of Obesogenic Behaviours on Adiposity in Spanish Children and Adolescents

\section{Disclosure Statement}

The authors declare no conflict of interest.

\section{References}

1 Sanchez-Cruz JJ, Jimenez-Moleon JJ, Fernandez-Quesada F, Sanchez MJ: Prevalence of child and youth obesity in Spain in 2012. Rev Esp Cardiol (Engl ed) 2013;66:371-376.

2 Schroder H, Ribas L, Koebnick C, Funtikova A, Gomez SF, Fito M, Perez-Rodrigo C, Serra-Majem L: Prevalence of abdominal obesity in Spanish children and adolescents. Do we need waist circumference measurements in pediatric practice? PloS One 2014;9:e87549.

3 Berenson GS: Cardiovascular risk begins in childhood: a time for action. Am J Prev Med 2009;37(1 suppl):S1-2.

4 Friedemann C, Heneghan C, Mahtani K, Thompson M, Perera R, Ward AM: Cardiovascular disease risk in healthy children and its association with body mass index: systematic review and meta-analysis. BMJ 2012; 345:e4759.

5 Deshmukh-Taskar P, Nicklas TA, Radcliffe JD, O'Neil CE, Liu Y: The relationship of breakfast skipping and type of breakfast consumed with overweight/obesity, abdominal obesity, other cardiometabolic risk factors and the metabolic syndrome in young adults. The National Health and Nutrition examination survey (NHANES): 1999-2006. Public Health Nutr 2013;16:073-2082.

6 Antonogeorgos G, Panagiotakos DB, Papadimitriou A, Priftis KN, Anthracopoulos M, Nicolaidou P: Breakfast consumption and meal frequency interaction with childhood obesity. Pediatr Obes 2012;7:65-72.

7 Ogunleye AA, Voss C, Sandercock GR: Prevalence of high screen time in English youth: association with deprivation and physical activity. J Public Health 2012;34:46-53.

8 Ministerio de sanida, servicios sociales e igualdad: Encuesta nacional de salud. España 2011/12. Actividad física, descanso y ocio. Serie informes monográficos no -4 . Ministerio de sanidad, servicios sociales e igualdad, 2014.

9 Food and Agriculture organization of the United Nations, Statistics Division: Consumer Price Indices. http:// faostat3.fao.org/download/P/CP/E (last accessed Novmeber 15, 2017).

10 Kaisari P, Yannakoulia M, Panagiotakos DB: Eating frequency and overweight and obesity in children and adolescents: a meta-analysis. Pediatrics 2013;131:958-967.

11 Horikawa C, Kodama S, Yachi Y, Heianza Y, Hirasawa R, Ibe Y, Saito K, Shimano H, Yamada N, Sone H: Skipping breakfast and prevalence of overweight and obesity in Asian and pacific regions: a meta-analysis. Prev Med 2011;53:260-267.

12 Boulos R, Vikre EK, Oppenheimer S, Chang H, Kanarek RB: Obesity: how television is influencing the obesity epidemic. Physiol Behav 2012;107:146-153.

13 Leech RM, McNaughton SA, Timperio A: The clustering of diet, physical activity and sedentary behavior in children and adolescents: a review. Int J Behav Nutr Phys Act 2014;11:4.

14 Hardy LL, Grunseit A, Khambalia A, Bell C, Wolfenden L, Milat AJ: Co-occurrence of obesogenic risk factors among adolescents. J Adolesc Health 2012;51: 265-271.

15 Sanchez A, Norman GJ, Sallis JF, Calfas KJ, Cella J, Patrick K: Patterns and correlates of physical activity and nutrition behaviors in adolescents. Am J Prev Med 2007;32:124-130.

16 Martinez-Gomez D, Moreno LA, Romeo J, Rey-Lopez P, Castillo R, Cabero MJ, Vicente-Rodriguez G, Gutierrez A, Veiga OL: Combined influence of lifestyle risk factors on body fat in Spanish adolescents - the AVENA study. Obes Facts 2011;4:105-111.

17 de Onis M, Onyango AW, Borghi E, Siyam A, Nishida C, Siekmann J: Development of a WHO growth reference for school-aged children and adolescents. Bull World Health Organ 2007;85:660-667.

18 Martínez-De-Haro V, Del-Campo J, Zapatera B, Welk GJ, Villagra A, Marcos A, Veiga OL: Validity of four questionnaires to assess physical activity in Spanish adolescents. Gac Sanit 2009;23:512-517.

19 Schofield WN: Predicting basal metabolic rate, new standards and review of previous work. Human nutrition. Clin Nutr 1985;39(suppl 1):5-41.

20 Liu K, Stamler J, Dyer A, McKeever J, McKeever P: Statistical methods to assess and minimize the role of intraindividual variability in obscuring the relationship between dietary lipids and serum cholesterol. J Chronic Dis 1978;31:399-418.

21 Goldberg GR, Black AE, Jebb SA, Cole TJ, Murgatroyd PR, Coward WA, Prentice AM: Critical evaluation of energy intake data using fundamental principles of energy physiology: 1. derivation of cut-off limits to identify underrecording. Eur J Clin Nutr 1991;45:569-581.

22 Black AE: Critical evaluation of energy intake using the Goldberg cut-off for energy intake: basal metabolic rate. A practical guide to its calculation, use and limitations. Int J Obes Relat Metab Disord 2000;24:11191130.

23 Nelson M, Black AE, Morris JA, Cole TJ: Between- and within-subject variation in nutrient intake from infancy to old age: estimating the number of days required to rank dietary intakes with desired precision. Am J Clin Nutr 1989;50:155-167. 
Schröder et al.: Cumulative Effect of Obesogenic Behaviours on Adiposity in Spanish Children and Adolescents

24 Torun B, Davies PS, Livingstone MB, Paolisso M, Sackett R, Spurr GB: Energy requirements and dietary energy recommendations for children and adolescents 1 to 18 years old. Eur J Clin Nutr 1996;50(suppl 1):S37-80; discussion S80-81.

25 Serra Majem L, Ribas Barba L, Aranceta Bartrina J, Pérez Rodrigo C, Saavedra Santana P, Peña Quintana L: Childhood and adolescent obesity in Spain. Results of the enKid study (1998-2000). Med Clin (Barc) 2003; 121:725-732.

26 Martínez RB, Aragonés Sanz N, Medrano Albero MJ: Tendencias en la mortalidad por cardiopatía isquémica en 50 provincias españolas Rev Esp Cardiol 2003;56:850-856

27 Lorenzo P, y Gil M, Rodríguez M: Mortalidad Evitable en las Islas Canarias. 1981-2005. Documento de referencia 1. III Plan de Salud de Canarias 2015-2017. www3.gobiernodecanarias.org/sanidad/scs/contenidoGenerico.jsp?idDocument $=c 5804547-31 b b-11 e 3-a 0 f 5-65699 e 4 f f 786 \& i d C a r p e t a=10 b 3 e a 46-541 b-11 d e-9665-$ 998e1388f7ed (last accessed November 15, 2017).

28 Logue J, Murray HM, Welsh P, Shepherd J, Packard C, Macfarlane P, Cobbe S, Ford I, Sattar N: Obesity is associated with fatal coronary heart disease independently of traditional risk factors and deprivation. Heart 2011; 97:564-568.

29 WHO Regional Office for Europe: Social Determinants of Health and Well-Being among Young People. Health Behaviour in School-Aged Children (HBSC) Study: International Report from the 2009/2010 Survey. Copenhagen, , 2012 www.euro.who.int/en/publications/abstracts/social-determinants-of-health-and-well-beingamong-young-people-health-behaviour-in-school-aged-children-hbsc-study (last accessed November 15, 2017).

30 St-Onge MP, Ard J, Baskin ML, Chiuve SE, Johnson HM, Kris-Etherton P, Varady K; American Heart Association Obesity Committee of the Council on Lifestyle and Cardiometabolic Health; Council on Cardiovascular Disease in the Young; Council on Clinical Cardiology; and Stroke Council: Meal timing and frequency: implications for cardiovascular disease prevention: a scientific statement from the American Heart Association. Circulation 2017;135:e96-e121.

31 Leech RM, Livingstone KM, Worsley A, Timperio A, McNaughton SA: Meal frequency but not snack frequency is associated with micronutrient intakes and overall diet quality in Australian men and women. J Nutr 2016; 146:2027-2034.

32 Ford ES, Bergmann MM, Kroger J, Schienkiewitz A, Weikert C, Boeing H: Healthy living is the best revenge: findings from the European prospective investigation into cancer and nutrition - Potsdam study. Arch Intern Med 2009;169:1355-1362.

33 Ford ES, Bergmann MM, Boeing H, Li C, Capewell S: Healthy lifestyle behaviors and all-cause mortality among adults in the united states. Prev Med 2012;55:23-27.

34 Aleksandrova K, Pischon T, Jenab M, Bueno-de-Mesquita HB, Fedirko V, Norat T, Romaguera D, Knuppel S, Boutron-Ruault MC, Dossus L, et al: Combined impact of healthy lifestyle factors on colorectal cancer: a large European cohort study. BMC Med 2014;12:168.

35 Reinehr T, Lass N, Toschke C, Rothermel J, Lanzinger S, Holl RW: Which amount of BMI-SDS reduction is necessary to improve cardiovascular risk factors in overweight children? J Clin Endocrinol Metab 2016;101: 3171-3179.

36 Kolsgaard ML, Joner G, Brunborg C, Anderssen SA, Tonstad S, Andersen LF: Reduction in BMI z-score and improvement in cardiometabolic risk factors in obese children and adolescents. The Oslo Adiposity Intervention Study - a hospital/public health nurse combined treatment. BMC Pediatr 2011;11:47.

37 Kelishadi R, Mirmoghtadaee P, Najafi H, Keikha M: Systematic review on the association of abdominal obesity in children and adolescents with cardio-metabolic risk factors. J Res Med Sci 2015;20:294-307.

38 Ogden CL, Lamb MM, Carroll MD, Flegal KM: Obesity and socioeconomic status in children and adolescents: United States, 2005-2008. NCHS Data Brief. 2010;51:1-8.

39 Driskell MM, Dyment S, Mauriello L, Castle P, Sherman K: Relationships among multiple behaviors for childhood and adolescent obesity prevention. Prev Med 2008;46:209-215.

40 Perez-Farinos N, Villar-Villalba C, Lopez Sobaler AM, Dal Re Saavedra MA, Aparicio A, Santos Sanz S, Robledo de Dios T, Castrodeza-Sanz JJ, Ortega Anta RM: The relationship between hours of sleep, screen time and frequency of food and drink consumption in Spain in the 2011 and 2013 ALADINO: a cross-sectional study. BMC Public Health 2017;17:33.

41 Roman-Vinas B, Marin J, Sanchez-Lopez M, Aznar S, Leis R, Aparicio-Ugarriza R, Schroder H, Ortiz-Moncada R, Vicente G, Gonzalez-Gross M, et al: Results from Spain's 2016 report card on physical activity for children and youth. J Phys Act Health 2016;13(11 suppl 2)S279-S283. 